\title{
Evaluation of the analgesic effects of ammoxetine, a novel potent serotonin and norepinephrine reuptake inhibitor
}

\author{
Ting-ting ZHANG ${ }^{1,2}$, Rui XUE², Lei ZHU ${ }^{1}$, Juan $\mathrm{LI}^{1}$, Qiong-yin FAN² ${ }^{2}$ Bo-hua ZHONG ${ }^{2}$, Yun-feng $\mathrm{LI}^{2}$, Cai-ying YE ${ }^{1, *}$, \\ You-zhi ZHANG ${ }^{2, *}$ \\ ${ }^{1}$ Department of Pharmacology, Institute of Basic Medical Sciences, Chinese Academy of Medical Sciences and Peking Union Medical \\ College, Beijing 100005, China; ${ }^{2}$ State Key Laboratory of Toxicology and Medical Countermeasures, Beijing Key Laboratory of \\ Neuropsychopharmacology, Beijing Institute of Pharmacology and Toxicology, Beijing 100850, China
}

Aim: The selective serotonin (5-HT) and norepinephrine (NE) reuptake inhibitors (SNRIs) are commonly used for the treatment of neuropathic pain and fibromyalgia. Ammoxetine (( \pm )-3-(benzo[d] [1,3]dioxol-4-yloxy)-N-methyl-3-(thiophen-2-yl)propan-1-amine) has been identified as a novel potent SNRI. In this study, we evaluated the acute analgesic properties of ammoxetine in different animal models of pain, and examined the involvement of monoamines in its analgesic actions.

Methods: The analgesic effects of ammoxetine were assayed using models of acetic acid- and formalin-induced pain in mice, neuropathic pain induced by sciatic nerve injury (SNI), chronic constriction injury $(\mathrm{CCl})$ and reserpine-induced fibromyalgia pain in rats. The contents of 5-HT and NE in brain regions of fibromyalgia rats were measured using HPLC-ECD. In all the experiments, duloxetine was used as a positive control drug.

Results: Oral administration of ammoxetine $(0.625-10 \mathrm{mg} / \mathrm{kg})$ or duloxetine $(2.5-40 \mathrm{mg} / \mathrm{kg})$ dose-dependently decreased the number of acetic acid-induced writhing and formalin-induced first phase and second phase paw licking time in mice. Oral administration of ammoxetine $(2.5-10 \mathrm{mg} / \mathrm{kg})$ or duloxetine $(10 \mathrm{mg} / \mathrm{kg})$ alleviated mechanical allodynia in SNI and CCI rats and thermal hyperalgesia in $\mathrm{CCl}$ rats. The antiallodynic effect of ammoxetine in $\mathrm{CCl}$ rats was abolished by pretreatment with para-chlorophenylalanine methyl ester hydrochloride (PCPA, a 5-HT synthesis inhibitor) or $\alpha$-methyl-para-tyrosine methylester (AMPT, a catecholamine synthesis inhibitor). Oral administration of ammoxetine $(30 \mathrm{mg} / \mathrm{kg})$ or duloxetine $(50 \mathrm{mg} / \mathrm{kg})$ significantly attenuated tactile allodynia in rats with reserpine-induced fibromyalgia. In the fibromyalgia rats, administration of ammoxetine (10, $30 \mathrm{mg} / \mathrm{kg})$ or duloxetine (30, $50 \mathrm{mg} / \mathrm{kg})$ dose-dependently increased the levels of 5-HT and NE, and decreased the metabolite ratio of 5-HT (5-HIAA/5-HT) in the spinal cord, hypothalamus, thalamus and prefrontal cortex.

Conclusion: Ammoxetine effectively alleviates inflammatory, continuous, neuropathic and fibromyalgia-related pain in animal models, which can be attributed to enhanced neurotransmission of 5-HT and NE in the descending inhibitory systems.

Keywords: ammoxetine; duloxetine; SNRIs; analgesia; neuropathic pain; fibromyalgia; 5-HT; NE; descending inhibitory system

Acta Pharmacologica Sinica (2016) 37: 1154-1165; doi: 10.1038/aps.2016.45; published online 18 Jul 2016

\section{Introduction}

Chronic pain is a debilitating disease and is estimated to be the third most prevalent health problem in the world. The treatment of pain is a great challenge, and new drugs are clearly needed for improved therapies. Clinically, chronic pain is frequently accompanied by affective disorders, such as depression and anxiety ${ }^{[1,2]}$. This combination suggests that

\footnotetext{
${ }^{*}$ To whom correspondence should be addressed.

E-mail caiyingye@126.com (Cai-ying YE); 13901363887@163.com (You-zhi ZHANG)

Received 2016-01-19 Accepted 2016-04-21
}

effective agents that exert pain reduction as well as mood improving effects would provide multiple benefits. Several decades of clinical investigations and experimental studies have shown the effectiveness of antidepressants in pain treatment ${ }^{[3-5]}$. The pain-relieving properties of antidepressants are considered to be mainly attributed to their potentiating effect on the descending pain-inhibitory pathways by inhibiting the reuptake of serotonin (5-HT) and norepinephrine $(\mathrm{NE})^{[6-8]}$.

Tricyclic antidepressants (TCAs) have been used for years for the treatment of neuropathic pain syndromes, including diabetic neuropathy, postherpetic neuralgia and migraine headaches ${ }^{[9,10]}$. However, the multifarious side effects of 
TCAs caused by targeting muscarinic, histaminergic and a-adrenergic receptors result in poor tolerability in chronic pain patients ${ }^{[11,12]}$. Selective serotonin reuptake inhibitors (SSRIs) or norepinephrine reuptake inhibitors (NRIs) are less effective in relieving pain ${ }^{[13-15]}$. Selective serotonin and norepinephrine reuptake inhibitors (SNRIs) have been the most promising agents in modulating pain symptoms because of their balanced effects on 5-HT and NE and their better tolerability $^{[16-19]}$.

The existing three SNRIs include venlafaxine, duloxetine and milnacipran. Duloxetine is the most commonly used SNRI that has been approved for the treatment of diabetic neuropathic pain (DNP), fibromyalgia and chronic musculoskeletal pain ${ }^{[20,21]}$. Although acting on the same targets, these drugs display some differences in their pharmacological profiles, and these differences might be responsible for their different clinical activities and limitations ${ }^{[22-24]}$. The development of new SNRIs might provide the opportunity to obtain compounds with improved clinical outcomes in patients suffering from depression and pain.

Ammoxetine is the $S-(-)$ isomer of 071031B (( \pm$)-3-($ benzo[d] [1,3] dioxol-4-yloxy)-N-methyl-3-(thiophen-2-yl)propan1-amine) and was described as a novel 5-HT and NE reuptake inhibitor $^{[25-27]}$. Our unpublished data proved that ammoxetine is a potent and selective SNRI with weak affinity to the DA (dopamine) transporter, monoamine oxidase, histamine, cholinergic, and 16 other GPCR opioid receptors. Ammoxetine could be detected in the plasma 5 min after being orally administered and is quickly distributed to the brain. Ammoxetine also displayed lower hepatotoxicity than duloxetine (data not shown). In the present study, we investigated the effects of ammoxetine on pain behavior induced by acetic acid or formalin in mice. The analgesic effects of ammoxetine on neuropathic pain and fibromyalgia were also assayed in sciatic nerve injury (SNI)/chronic constriction injury (CCI) and reserpine treated rats, respectively. Moreover, we examined the involvement of monoamines in the mechanisms of the analgesic effects of ammoxetine in CCI rats and reserpine-induced

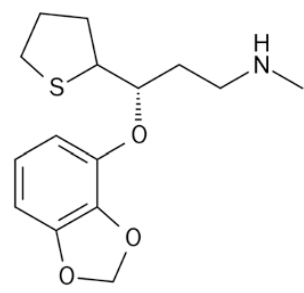

Figure 1. Chemical structure of ammoxetine.

fibromyalgia rats.

\section{Materials and methods}

Animals

Animals were purchased from the Beijing Vital River Laboratory Animal Technology Company (Beijing, China). Male KM mice weighing 22-25 g were used for the acetic acid writhing test and formalin test. Male Sprague-Dawley rats weighing 180-200 g were used for sciatic nerve injury models, and rats weighing 250-300 g were used for the fibromyalgia experiments. The animals were group-housed under a 12-h light/ dark cycle at room temperature $\left(23 \pm 1^{\circ} \mathrm{C}\right)$ with free access to food and water. All experiments were conducted according to the National Research Council's guidelines.

\section{Drugs}

Duloxetine hydrochloride was purchased from Shanghai Wandai Pharmaceutical Corporation, Ltd (Taizhou, China). Ammoxetine was synthesized in our institute (Beijing Institute of Pharmacology and Toxicology). Gabapentin, para-chlorophenylalanine methyl ester hydrochloride (PCPA), a-methylpara-tyrosine methyl ester (AMPT), reserpine hydrochloride, 5-HT, dopamine (DA), NE, 5-hydroxyindole-3-acetic acid (5-HIAA), homovanillic acid (HVA) and 3,4-dihydroxyphenylacetic acid (DOPAC) were purchased from Sigma-Aldrich (St Louis, MO, USA). Ammoxetine, duloxetine and gabapentin were dissolved in distilled water. PCPA was suspended in distilled water with 5\% Tween-80. AMPT was dissolved in saline. Reserpine was dissolved in glacial acetic acid and diluted to a final concentration of $0.5 \%$ acetic acid with distilled water. All drugs were administered subcutaneously (sc), intraperitoneally (ip), or orally ( $p o$ ) by gavage at concentrations of $1.0 \mathrm{~mL} / \mathrm{kg}$ for rats and $10 \mathrm{~mL} / \mathrm{kg}$ for mice. The doses for each drug used in experiment are discussed below.

\section{Acetic acid writhing test in mice}

Separate groups of 12 mice were pretreated (po) with duloxetine $(2.5-40 \mathrm{mg} / \mathrm{kg})$, ammoxetine $(0.625-10 \mathrm{mg} / \mathrm{kg})$ or the vehicle and were injected (ip) 30 min later with $2 \%$ acetic acid (solution in water) at a concentration of $10 \mathrm{~mL} / \mathrm{kg}$. Each mouse was then housed in an individual clear plastic observation chamber. The numbers of writhes were counted between 5 and 20 min after the acetic acid injection. A writhe was defined as stretching of the hind limbs accompanied by a contraction of the abdominal muscles ${ }^{[28]}$.

\section{Formalin test in mice}

Separate groups of 10 mice weighing 22-25 g were acclimatized to individual cubicles for at least $20 \mathrm{~min}$ prior to the experiment. Mice were pretreated ( $p o$ ) with duloxetine (2.5-40 $\mathrm{mg} / \mathrm{kg})$, ammoxetine $(1.25-20 \mathrm{mg} / \mathrm{kg}$ ) or the vehicle and were injected (sc) 30 min later with formalin $(20 \mu \mathrm{L}$ of a $5 \%$ solution in saline) into the dorsal lateral surface of the right hind paw using a 30-G needle. Observations started immediately after the formalin injection, and nociception was quantified based on the total paw licking time in seconds in the first phase (0-5 $\mathrm{min})$ and the second phase $(15-35 \mathrm{~min})^{[29]}$.

\section{SNI procedures}

Spared nerve injury was induced in rats according to Decosterd and Woolf ${ }^{[30]}$. Male Sprague-Dawley rats (180-200 g) were anesthetized with $7 \%$ chloral hydrate. After shaving and cleaning the left hind leg, the sciatic nerve was exposed 
at the level of trifurcation into the sural, tibial, and common peroneal nerves. The branches of the tibial and common peroneal nerves were tightly ligated and severed, keeping the sural nerve intact. The overlying muscle and skin were closed with silk thread. The same surgical operations were performed in the sham group of animals, although the nerve was only exposed and not cut. After recovery, the rats were housed in groups of 3-5 individuals. Baseline mechanical allodynia thresholds were determined prior to SNI surgery. Drug evaluation was performed $10 \mathrm{~d}$ after SNI surgery, when mechanical allodynia was near the maximum. The pre-drug withdrawal thresholds were measured, and animals that displayed an increased mechanical sensitivity of more than $40 \%$ of the base values were allocated to groups equally to minimize the differences in the average thresholds among the groups $(n=10 /$ group). Rats received a single dose of ammoxetine (2.5, 5 and $10 \mathrm{mg} / \mathrm{kg}$, po), duloxetine $(10 \mathrm{mg} / \mathrm{kg}$, po) or the vehicle. The withdrawal thresholds were again determined at 30,60, 120 and $180 \mathrm{~min}$ post drug administration.

\section{CCI procedures}

CCI surgery was performed according to the method of Bennett and $\mathrm{Xie}^{[31]}$. Male Sprague-Dawley rats (180-200 g) were anesthetized with $7 \%$ chloral hydrate. After shaving and cleaning the left hind leg, the left common sciatic nerve was exposed at the level of the mid-thigh through the biceps femoris. The nerve was separated from the adhering tissue proximal to the sciatic trifurcation. Four chromic gut ligatures $(4 / 0)$ (JINHUAN, Shanghai, China) were tied loosely around the nerve, 1-2 mm apart. The same surgical operations were performed in the sham group of animals except for the addition of the ligatures. The mechanical allodynia thresholds were determined before and $14 \mathrm{~d}$ after the CCI surgery. Animals that displayed an increased mechanical sensitivity of more than $40 \%$ of the base values were allocated to groups equally ( $n=10 /$ group). Before drug administration, thermal hyperalgesia was determined. The acute antinociceptive effects of ammoxetine $(2.5,5$ and $10 \mathrm{mg} / \mathrm{kg}$, po), duloxetine $(10$ $\mathrm{mg} / \mathrm{kg}, \mathrm{po})$ or gabapentin $(60 \mathrm{mg} / \mathrm{kg}$, po) were determined. The mechanical allodynia thresholds were tested 30, 60, 120 and $180 \mathrm{~min}$ after a single dose of drug administration, and thermal hyperalgesia was tested 180 min post-drug administration.

\section{The effects of PCPA and AMPT on the antinociception of ammoxetine}

The potential contribution of the serotonergic system to the pharmacological effect of ammoxetine was investigated using PCPA (an inhibitor of 5-HT synthesis), and the possible involvement of the catecholaminergic system was examined using AMPT (an inhibitor of catecholamine synthesis). PCPA $(150 \mathrm{mg} / \mathrm{kg}$, ip) or $5 \%$ Tween- 80 was administered to CCI rats for three consecutive days before the administration of ammoxetine $(10 \mathrm{mg} / \mathrm{kg}, \mathrm{po})$ or distilled water. In a separate group, AMPT (200 mg/ kg, ip) or saline was injected into CCI rats $24 \mathrm{~h}$ and $1 \mathrm{~h}$ before ammoxetine or distilled water. The mechanical allodynia thresholds in CCI rats were tested before and after PCPA or AMPT administration. The acute antinociceptive effects of ammoxetine were then determined.

\section{Mechanical allodynia (von Frey hair test)}

The cutaneous nociceptive threshold of the operated hind paws was assessed according to a previous method reported by Chaplan ${ }^{[32]}$. Briefly, rats were placed in test cages with a metal-mesh floor and were allowed to habituate for at least $30 \mathrm{~min}$. Von Frey filaments (Touch-Test ${ }^{\circledR}$ Sensory Evaluators, NC12775-99, North Coast Medical Inc, San Jose, CA, USA) of $0.6,1.0,1.4,2.0,4.0,6.0,8.0,10.0,15.0$ and $26.0 \mathrm{~g}$ were applied to the plantar surface of the left hind paw. A positive or negative response was defined as a paw withdrawal response from the pressure of a filament or the lack of a response within $6 \mathrm{~s}$, respectively. Initially, a $2.0-\mathrm{g}$ force filament was used for the nerve-injured rats, and a $6.0-\mathrm{g}$ force filament was used for the sham rats. If a positive response to a given filament occurred, the next-smaller filament was then used. If a negative response occurred, the next-larger filament was used. The test continued until four responses were collected after the first change in response. The tactile stimulus producing a 50\% likelihood of paw withdrawal threshold (PWT) was used to calculate the cutaneous nociceptive threshold using an adaptation of the Dixon up-down paradigm.

\section{Thermal hyperalgesia (Plantar test)}

Thermal hyperalgesia was assessed using the plantar test (Model 390 G; IITC Life Science Inc, Woodland Hills, CA, USA) and a modified method of Hargreaves ${ }^{[33]}$. In brief, the rats were habituated to an apparatus consisting of individual Perspex boxes placed on top of a heated glass plate $\left(30 \pm 1^{\circ} \mathrm{C}\right)$. A mobile radiant heat source was positioned under the glass. A focused beam of radiant light (active intensity of 30\%) was used to heat the plantar surface of the hind paw. The pawwithdrawal latency was defined as the time taken by the rat to remove its hind paw from the heat source. The cut-off point was set at $20 \mathrm{~s}$ to prevent tissue damage. The injured hind paws were tested 3 times, and the average withdrawal latency was calculated and used for the analysis.

\section{Rotarod test}

The potential effect of ammoxetine on motor performance was examined in normal uninjured rats at doses of 2.5, 5 and $10 \mathrm{mg} / \mathrm{kg}$ and in reserpine-treated rats at $30 \mathrm{mg} / \mathrm{kg}$ using an accelerating rotarod (TSE 337500, Germany) test. The rotarod speed was increased from 4 to $40 \mathrm{r} / \mathrm{min}$ over a $300 \mathrm{~s}$ period, with the maximum time spent on the rotarod set at $300 \mathrm{~s}$. The rats received two training trials on the first day (separated by $3-4 \mathrm{~h}$ ) prior to drug testing for acclimatization purposes. On the day of testing, a baseline response was obtained, and the rats were grouped to minimize the differences among groups. The rats received a single dose of duloxetine, ammoxetine or vehicle and were tested 1 and $3 \mathrm{~h}$ later. 


\section{Induction of fibromyalgia by reserpine injection}

Fibromyalgia was induced in rats following Nagakura's method $^{[34]}$. Generally, reserpine was subcutaneously injected at a dose of $1 \mathrm{mg} / \mathrm{kg}$ once daily for three consecutive days. It has been shown that reserpine treatment causes significant tremors, hypokinesia and decreased body weight. Food pellets were placed on the floor of the cage after reserpine injection to allow for easier feeding. The effects of the drugs were evaluated $5 \mathrm{~d}$ after the last injection of reserpine. The predrug tactile response thresholds were measured, and rats with a threshold of less than $5 \mathrm{~g}$ were selected and allocated equally into 5 groups, each of which received ammoxetine (10 and 30 $\mathrm{mg} / \mathrm{kg}, p o$ ), duloxetine (30 and $50 \mathrm{mg} / \mathrm{kg}$, po) or the vehicle. The response thresholds were again measured $0.5,1,2$ and $4 \mathrm{~h}$ after the administration of drugs or the vehicle.

\section{Monoamine assays in brain regions in fibromyalgia rats by HPLC-} ECD

The content of monoamines including 5-HT and its metabolite 5-HIAA, NE, DA and its metabolites DOPAC and HVA in tissues was analyzed using HPLC-ECD as previously described $^{[25]}$. Fibromyalgia rats treated with ammoxetine and duloxetine were euthanized immediately after the tactile test. After the prompt removal of the brains and spinal cords, the hypothalamus, thalamus and prefrontal cortex were dissected out on an ice-cold dish. The samples were immediately frozen and stored in liquid nitrogen until assayed. The samples were weighed and homogenized in $0.4 \mathrm{~mol} / \mathrm{L}$ perchloric acid with $0.5 \mathrm{mmol} / \mathrm{L} \mathrm{Na}_{2}$-EDTA and $0.01 \%$ L-cysteine $(10 \mathrm{~mL} / \mathrm{mg}$ of tissue) and then centrifuged at $12000 \mathrm{r} / \mathrm{min}$ for $30 \mathrm{~min}$ at $4{ }^{\circ} \mathrm{C}$. The supernatant was filtered and injected into the HPLC system, which consisted of a microbore reverse-phase column (particle size $5 \mu \mathrm{m}, 250 \mathrm{~mm} \times 4.6 \mathrm{~mm}$ ), a Waters e2465 pump (flow rate $1.0 \mathrm{~mL} / \mathrm{min}$ ) and an e2695 electrochemical detector with a VT03 flow cell glassy carbon working electrode set at $700 \mathrm{mV}$ (with respect to an $\mathrm{Ag} / \mathrm{AgCl}$ reference electrode). All HPLC components and software were purchased from Waters Technologies (Shanghai, China). The mobile phase ( $\mathrm{pH}$ 3.7) consisted of $85 \mathrm{mmol} / \mathrm{L}$ citrate, $100 \mathrm{mmol} / \mathrm{L}$ sodium acetate, $0.9 \mathrm{mmol} / \mathrm{L}$ octyl-sodium sulfate, $0.2 \mathrm{mmol} / \mathrm{L}$ EDTA, and 15\% methanol. External standard curves were used for sample quantitation based on the area under curve. The injection volume was $50 \mu \mathrm{L}$.

\section{Statistical analysis}

The statistical analysis was performed using GraphPad Prism
(GraphPad Prism 5.0, version 2.0; GraphPad Software Inc, San Diego, CA, USA). The data are expressed as the mean \pm SEM. The data from the writhing and formalin tests and the monoamine levels measured by HPLC were analyzed using Student's t-test or a one-way analysis of variance (ANOVA) followed by Dunnett's test. For data exhibiting unequal variances, a Mann-Whitney U-test or a Kruskal-Wallis test followed by Dunn's Multiple Comparison Test was applied. The $\mathrm{ED}_{50}$ values were determined using a triple-parameter logistic equation. The $\mathrm{ED}_{50}$ was defined as the dose that produced $50 \%$ of the maximum possible effect. For the data obtained from the time-course measurement studies (SNI, CCI, reserpine induced fibromyalgia), analyses were conducted using two-way repeated-measures ANOVA followed by Bonferroni's post-hoc analysis. The data for the PWTs before and after administration with PCPA or AMPT were compared by a paired $t$-test. Probability values of less than 0.05 were considered statistically significant.

\section{Results}

Ammoxetine attenuated pain behavior induced by acetic acid or formalin

In the acetic acid-induced writhing test, compared with vehicle treatment, oral administration of ammoxetine (0.625-10 $\mathrm{mg} / \mathrm{kg}$ ) reduced the number of writhing events (Kruskal-Wallis test, Kruskal-Wallis statistic $=36.67, P<0.01$, Dunn's Multiple Comparison Test, $P<0.05$ for 2.5 and $5 \mathrm{mg} / \mathrm{kg}, P<0.01$ for 10 $\mathrm{mg} / \mathrm{kg})$. Duloxetine $(2.5-40 \mathrm{mg} / \mathrm{kg}$ ) reduced the number of writhing events (Kruskal-Wallis test, Kruskal-Wallis statistic $=20.26, P=0.0011$, Dunn's Multiple Comparison Test, $P<0.05$ for $20 \mathrm{mg} / \mathrm{kg}, P<0.01$ for $40 \mathrm{mg} / \mathrm{kg})$. The $\mathrm{ED}_{50}( \pm 95 \% \mathrm{CL})$ values of reversing the writhing behavior were $2.01(0-7.06)$ $\mathrm{mg} / \mathrm{kg}$ for ammoxetine and 10.03 (6.94-13.10) $\mathrm{mg} / \mathrm{kg}$ for duloxetine (Table 1, Figure 2).

The analgesic effect of ammoxetine was further evaluated by a formalin test. Ammoxetine (1.25-20 mg/ kg) dose dependently reduced the paw licking time in both the first and the second phases (one-way ANOVA, first phase: $F_{5,54}=5.40$, $P=0.0004$, Dunn's Multiple Comparison Test, $P<0.01$ for 10 and $20 \mathrm{mg} / \mathrm{kg}$; second phase: $F_{5,53}=9.182, P<0.01$, Dunn's Multiple Comparison Test, $P<0.01$ for 5, 10 and $20 \mathrm{mg} / \mathrm{kg}$ ). Duloxetine $(2.5-40 \mathrm{mg} / \mathrm{kg})$ also reduced both the first and the second phases of the paw licking time (one-way ANOVA, first phase: $F_{5,54}=7.78, P<0.01$, Dunn's Multiple Comparison Test, $P<0.01$ for 20 and $40 \mathrm{mg} / \mathrm{kg}$; second phase: $F_{5,53}=14.67, P<0.0001$, Dunn's Multiple Comparison Test, $P<0.01$ for 10, 20 and 40

Table 1. The $\mathrm{ED}_{50}$ values $(\mathrm{mg} / \mathrm{kg}$ ) and $95 \%$ confidence limits for the effects of ammoxetine and duloxetine in the acetic acid test and formalin test.

\begin{tabular}{lcrr}
\hline Compound & & \multirow{2}{*}{$\mathrm{ED}_{50}( \pm 95 \% \mathrm{CL})(\mathrm{mg} / \mathrm{kg})$} & Formalin test \\
& Acetic acid test & First phase & Second phase \\
\hline Ammoxetine & $2.01(0-7.06)$ & $9.89(6.55-13.23)$ & $4.74(2.84-6.64)$ \\
Duloxetine & $10.03(6.94-13.10)$ & $19.65(14.52-24.79)$ & $10.06(9.13-11.00)$ \\
\hline
\end{tabular}



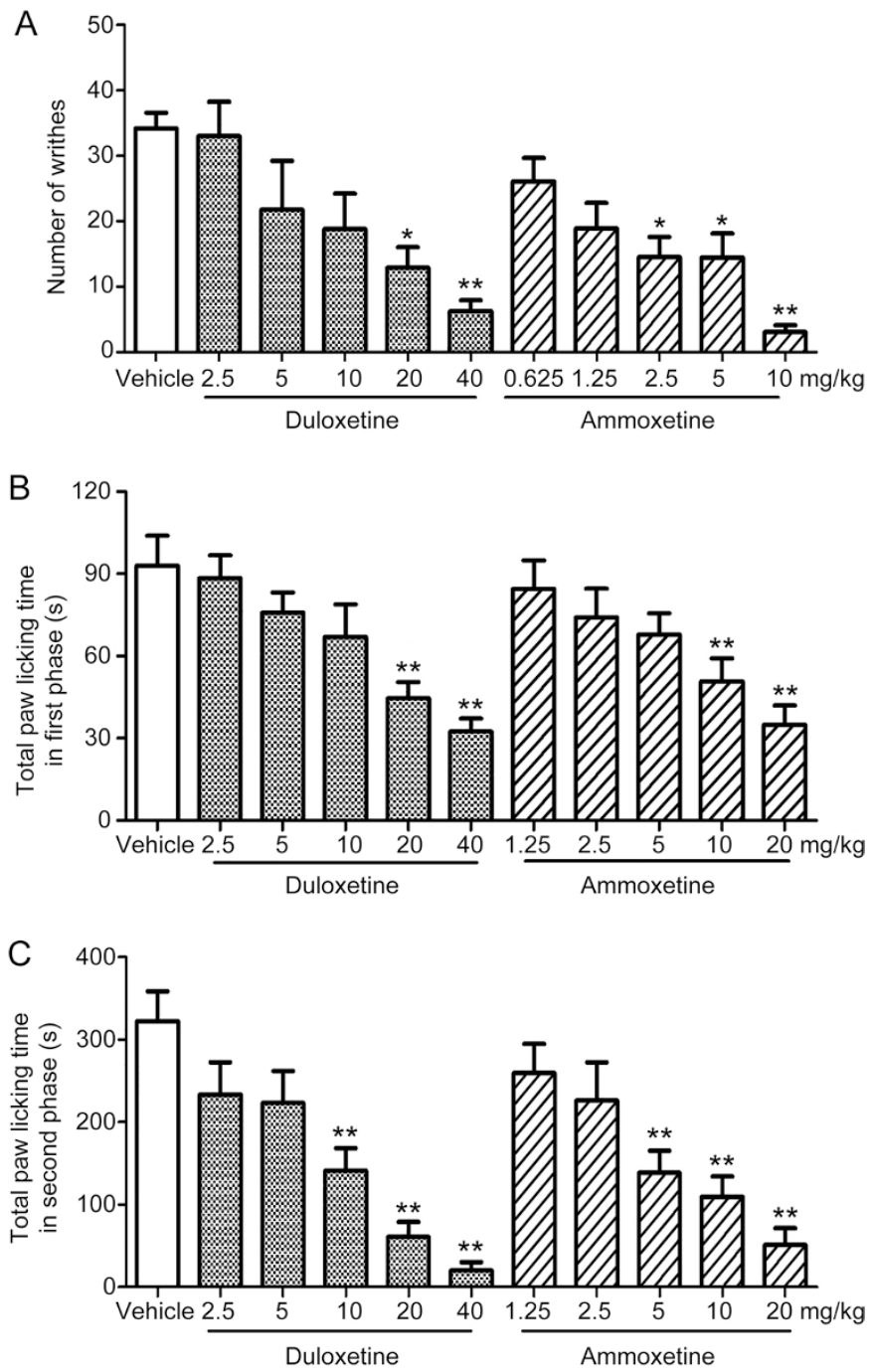

Figure 2. Analgesic effects of ammoxetine and duloxetine in acetic acidinduced writhing test and formalin test in mice. (A) Ammoxetine and duloxetine decreased the number of writhing events induced by acetic acid $(n=10-12)$. (B) Ammoxetine and duloxetine dose-dependently decreased the total licking times in the first phase in formalin test $(n=10)$. (C) Ammoxetine and duloxetine decreased the total licking time in the second phase in formalin test $(n=10)$. Data are presented as the mean \pm SEM. ${ }^{*} P<0.05,{ }^{* *} P<0.01$ vs the vehicle-treated group.

$\mathrm{mg} / \mathrm{kg})$. The $\mathrm{ED}_{50}( \pm 95 \% \mathrm{CL})$ values in reversing the licking time for ammoxetine were $9.89(6.55-13.23) \mathrm{mg} / \mathrm{kg}$ for the first phase and 4.74 (2.84-6.64) $\mathrm{mg} / \mathrm{kg}$ for the second phase. The $\mathrm{ED}_{50}( \pm 95 \% \mathrm{CL})$ values in reversing the licking time for duloxetine were $19.65(14.52-24.79) \mathrm{mg} / \mathrm{kg}$ for the first phase and 10.06 (9.13-11.00) $\mathrm{mg} / \mathrm{kg}$ for the second phase (Table 1, Figure 2 ).

\section{Ammoxetine produced analgesia in pain induced by sciatic nerve injury}

We investigated if ammoxetine exerts an analgesic effect on neuropathic pain using models of SNI and CCI. The SNI rats showed a significant decrease in the mechanical threshold compared with the age-matched sham animals (treatment: $F_{5,50}=51.59, P<0.01$; time: $F_{4,50}=15.78, P<0.01$; treatment $\times$ time: $\left.F_{20,50}=3.74, P<0.01\right)$. Ammoxetine displayed a significant painrelieving effect. Orally administered ammoxetine at a dose of $5 \mathrm{mg} / \mathrm{kg}$ increased the PWT at the 30,60, and $120 \mathrm{~min}$ time points. Ammoxetine $(10 \mathrm{mg} / \mathrm{kg})$ significantly elevated the PWT at 30, 60, 120 and 180 min post-administration. Duloxetine $(10 \mathrm{mg} / \mathrm{kg})$ caused a significant reversal of allodynia at 60, 120 and 180 min post-administration (Figure 3A).

CCI induced tactile allodynia and thermal hyperalgesia in rats; the mechanical threshold (treatment: $F_{6,63}=23.25, P<0.01$; time: $F_{4,63}=14.72, P<0.01$; treatment $\times$ time: $F_{24,63}=2.76, P<0.0001$ ) and thermal latency (treatment: $F_{6,58}=10.91, P<0.01$; time: $F_{1,58}=53.26, P<0.0001$; treatment $\times$ time: $\left.F_{6,58}=4.16, P=0.0015\right)$ were decreased in operated rats compared with the sham group animals. Ammoxetine displayed a pain-relieving effect on mechanical allodynia in CCI rats. Ammoxetine increased the PWT at 30, 60, 120 and $180 \mathrm{~min}$ after administration at doses of 5 and $10 \mathrm{mg} / \mathrm{kg}$. A statistically significant increase in the PWT was observed only at 120 min post-administration of duloxetine $(10 \mathrm{mg} / \mathrm{kg})$. Considering the undefined efficacy of duloxetine, gabapentin was used as the positive control. Gabapentin $(60 \mathrm{mg} / \mathrm{kg})$ produced a significant reversal of allodynia at 30,60, 120 and 180 min post-administration (Figure 3B).

Ammoxetine $(10 \mathrm{mg} / \mathrm{kg})$ significantly increased the paw withdrawal latency in the plantar test in CCI rats at $180 \mathrm{~min}$ post-administration. Gabapentin $(60 \mathrm{mg} / \mathrm{kg})$ and duloxetine $(10 \mathrm{mg} / \mathrm{kg})$ also produced significant reversals of thermal hyperalgesia at $180 \mathrm{~min}$ post-administration (Figure 3C).

We tested the motor function using the accelerating rotarod assay to eliminate the possibility that motor impairment accounted for the analgesic effects of ammoxetine. The oral administration of ammoxetine $(2.5,5$ and $10 \mathrm{mg} / \mathrm{kg})$ or duloxetine $(10 \mathrm{mg} / \mathrm{kg})$ did not affect the latency in the rotarod test in rats (treatment: $F_{4,35}=0.06, P>0.05$; time: $F_{2,105}=11.01$, $P<0.001$; treatment $\times$ time: $F_{8,119}=0.22, P>0.05$ ) (Figure 3D).

\section{Pretreatment with PCPA or AMPT abolished the pain-relieving effect of ammoxetine}

We evaluated the effect of pretreatment with PCPA (an inhibitor of 5-HT synthesis) or AMPT (an inhibitor of catecholamine synthesis) on the analgesia elicited by ammoxetine (10 $\mathrm{mg} / \mathrm{kg}$ ) in CCI rats. The administration of PCPA did not modify the PWT (paired $t$-test, $t=0.3363, P=0.74$ ) in CCI rats (Figure 4A1). Ammoxetine increased the PWT in CCI rats pretreated with 5\% Tween-80 (treatment: $F_{1,10}=32.14, P<0.01$; time: $F_{4,50}=3.31, P<0.05$; treatment $\times$ time: $\left.F_{4,59}=6.09, P<0.01\right)$. The effect of ammoxetine on the PWT in CCI rats pretreated with PCPA was not significant (treatment: $F_{1,10}=7.34, P>0.05$; time: $F_{4,50}=0.67, P>0.05$; treatment $\times$ time: $F_{4,59}=0.65, P>0.05$ ) (Figure 4A2). The paired $t$-test showed that treatment with AMPT had no significant effect on the PWT in CCI rats (paired $t$-test, $t=0.9778, P>0.05$ ) (Figure 4B1). Ammoxetine increased the PWT in CCI rats pretreated with saline (treatment: 

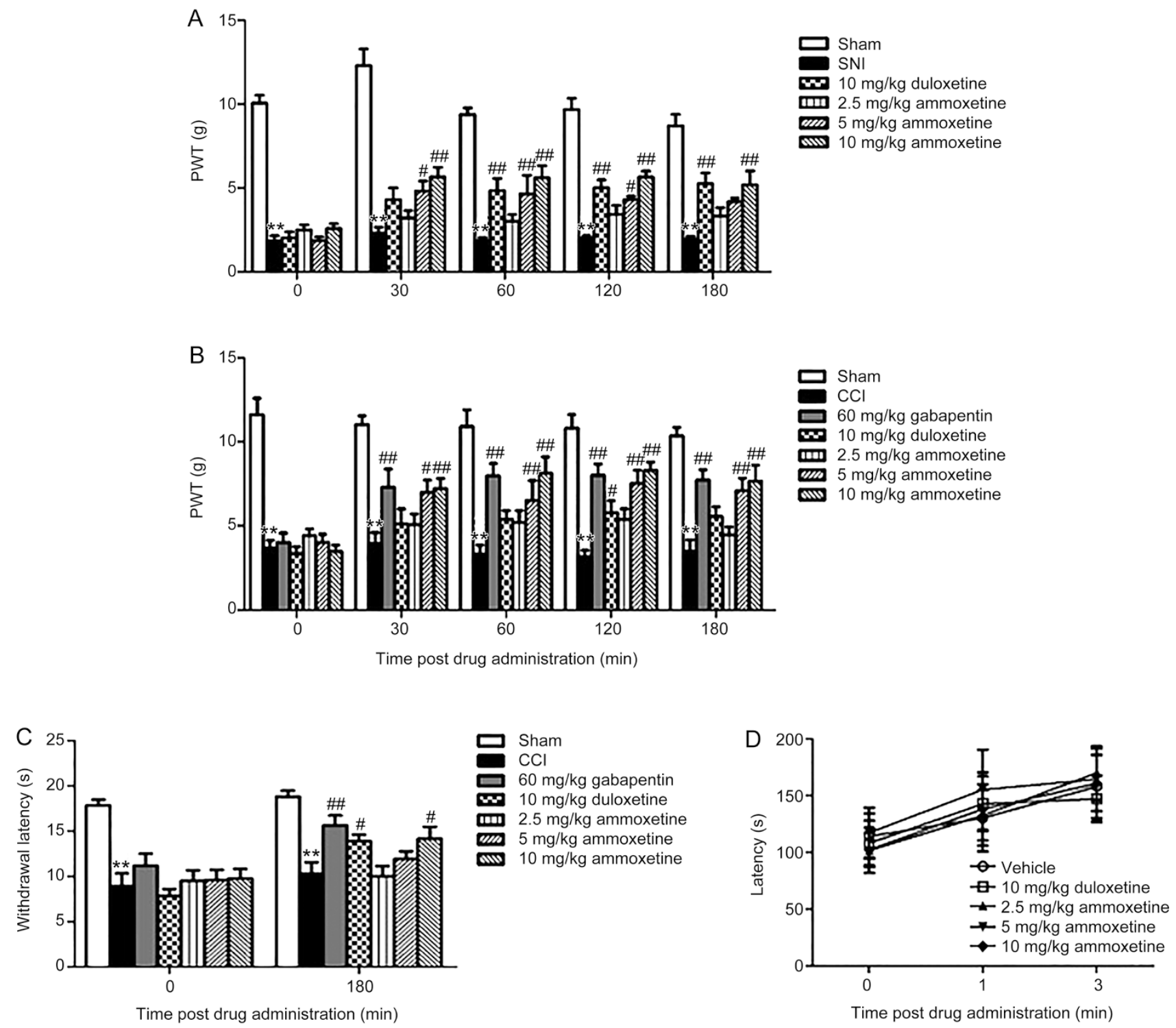

Figure 3. Analgesic effects of ammoxetine on neuropathic pain in the rat models of SNI and CCl. (A) Ammoxetine increased the PWT measured by the von Frey hair test in SNI rats $(n=10)$. (B) Ammoxetine increased the PWT in CCl rats $(n=10)$. (C) Ammoxetine increased the paw withdrawal latency in response to thermal stimulation in $\mathrm{CCl}$ rats $(n=8-10)$. (D) Time course of the effects of ammoxetine and duloxetine on the rotarod test in rats ( $n=8$ ). Data are presented as the mean \pm SEM. ${ }^{* *} P<0.01$ vs the sham group at the same time point. ${ }^{\#} P<0.05,{ }^{\# \#} P<0.01$ vs the SNI group or the CCl group at the same time point.

$F_{1,10}=16.96, P<0.01$; time: $F_{4,50}=3.86, P<0.01$; treatment $\times$ time: $\left.F_{4,59}=5.70, P<0.01\right)$. The effect of ammoxetine on the PWT in CCI rats pretreated with AMPT was not significant (treatment: $F_{1,10}=0.06, P>0.05$; time: $F_{4,10}=0.69, P>0.05$; treatment $\times$ time: $F_{1,10}=0.51, P>0.05$ ) (Figure 4B2).

\section{Analgesia effects of ammoxetine on fibromyalgia induced by} reserpine

A previous study revealed that the withdrawal threshold reached its lowest level at 4-7 d after the last injection of reserpine $(1 \mathrm{mg} / \mathrm{kg} \text { once daily for three consecutive days })^{[35]}$. We evaluated the pain relieving effects of the drugs five days after the last injection of reserpine. Reserpine treatment significantly decreased the PWT in rats compared with the healthy controls (treatment: $F_{5,54}=50.63, P<0.01$; time: $F_{4,270}=10.34$, $P<0.001$; treatment $\times$ time: $\left.F_{20,299}=1.51, P<0.01\right)$. Ammoxetine at a dose of $30 \mathrm{mg} / \mathrm{kg}$ significantly increased the PWT at 60 , 120 and $180 \mathrm{~min}$ post-administration. Duloxetine produced a significant reversal of mechanical allodynia at a dose of 50 $\mathrm{mg} / \mathrm{kg}$ at 60,120 and $180 \mathrm{~min}$ post-administration (Figure 5A). There was no difference in the motor performance between the reserpine-treated rats and the healthy control rats (treatment: $F_{3,20}=0.23, P>0.05$; time: $F_{2,60}=1.28, P>0.05$; treatment $\times$ time: $\left.F_{6,71}=0.21, P>0.05\right)$. The administration of ammoxetine (30 

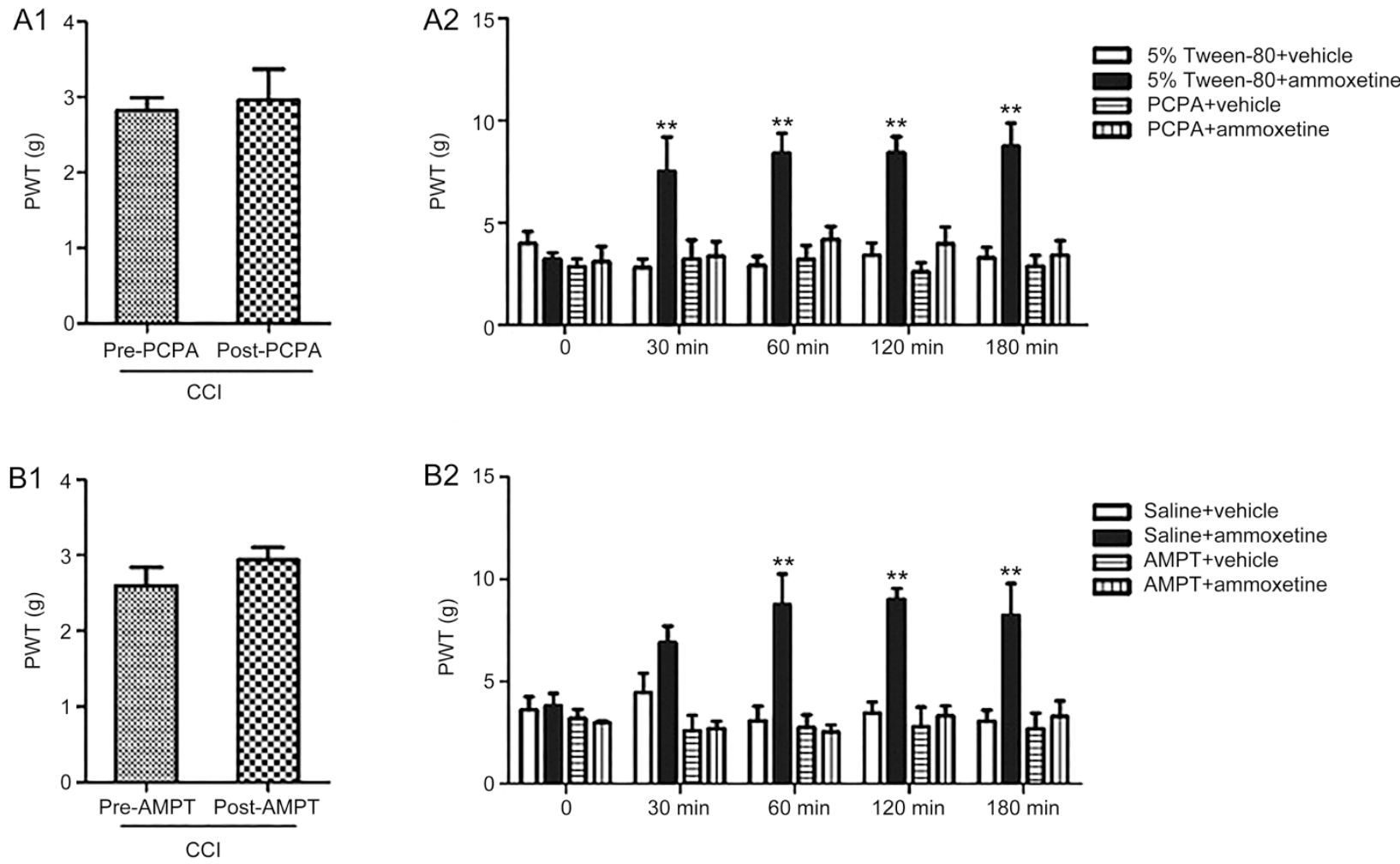

Figure 4. Pretreatment of either PCPA or AMPT abolished the pain relieving effect of ammoxetine in $\mathrm{CCl}$ rats. (A) PCPA had no effect on the PWT in $\mathrm{CCl}$ rats $(\mathrm{A} 1, n=12)$ and abolished the effect of ammoxetine on the PWT in $\mathrm{CCl}$ rats $(\mathrm{A} 2, n=6)$. ${ }^{* *} P<0.01$ vs $5 \%$ Tween-80+vehicle. (B) Administration of AMPT had no effect on the PWT in $\mathrm{CCl}$ rats $(\mathrm{B} 1, n=12)$ and abolished the effect of ammoxetine on the PWT in $\mathrm{CCl}$ rats $(\mathrm{B} 2, n=6)$. ${ }^{* *} P<0.01$ vs Saline+vehicle. Data are presented as the mean \pm SEM.

$\mathrm{mg} / \mathrm{kg}$ ) or duloxetine $(50 \mathrm{mg} / \mathrm{kg})$ did not affect the motor function in the reserpine-treated rats in the rotarod test (Figure $5 B)$.

Effects of ammoxetine on the levels of monoamines in the spinal cord and brain in reserpine-treated rats

The levels of monoamine transmitters (5-HT, NE, DA) and the metabolite ratios of 5-HT and DA (5-HIAA/5-HT and DOPAC/DA) in the spinal cord and brain regions, including the hypothalamus, thalamus and prefrontal cortex, in reserpine-treated rats are summarized in Table 1 . The measured values of DA and DOPAC were lower than the minimum detection values in the spinal cord, and the chromatographic peaks of HVA were not detectable in some samples in our detection system. Therefore, the DOPAC/DA values in the spinal cord and levels of HVA were not determined. When compared with the healthy control rats, the levels of 5-HT, NE and DA in reserpine-treated rats were significantly decreased in the spinal cord (5-HT, Mann-Whitney test, $U=2.000$, $P<0.0317$; NE, Mann-Whitney test, $U=0.000, P=0.0022)$, hypothalamus (5-HT, Student's $t$-test, $t=11.42, P<0.01$; NE, Student's $t$-test, $t=7.163, P<0.01$; DA, Student's $t$-test, $t=10.67, P<0.01)$, thalamus (5-HT, Student's $t$-test, $t=17.67, P<0.01$; NE, MannWhitney test, $U=0.000, P=0.0043$; DA, Mann-Whitney test, $U=0.000, P=0.0022)$ and prefrontal cortex (5-HT, Mann-Whit- ney test, $U=0.000, P=0.0022$; NE, Mann-Whitney test, $U=0.000$, $P=0.0022$; DA, Mann-Whitney test, $U=0.000, P=0.0022)$. The 5-HIAA/5-HT and DOPAC/DA ratios in the reserpine-treated rats were significantly increased relative to the control rats in the spinal cord (5-HIAA/5-HT, Student's $t$-test, $t=8.883$, $P<0.0001)$, hypothalamus (5-HIAA/5-HT, Mann-Whitney test, $U=0.000, P=0.0022$; DOPAC/DA, Mann-Whitney test, $U=0.000$, $p=0.0022)$, thalamus (5-HIAA/5-HT, Mann-Whitney test, $U=0.000, P=0.0022$; DOPAC/DA, Mann-Whitney test, $U=0.000$, $P=0.0022)$ and prefrontal cortex (5-HIAA/5-HT, Student's $t$-test, $t=12.55, P<0.0001$; DOPAC $/ D A$, Student's $t$-test, $t=3.072$, $P=0.0118$ ) (Table 2).

In the spinal cord, orally administered ammoxetine increased the levels of NE (Kruskal-Wallis test, Kruskal-Wallis statistic $=6.214, P=0.0205$, Dunn's Multiple Comparison Test, $P<0.05$ for $30 \mathrm{mg} / \mathrm{kg}$ ammoxetine) and reversed the effects of reserpine on the 5-HIAA/5-HT ratio (one-way ANOVA, $F_{2,15}=32.76, P<0.001$, Dunn's Multiple Comparison Test, $P<0.01$ for $10 \mathrm{mg} / \mathrm{kg}$ ammoxetine and $P<0.01$ for $30 \mathrm{mg} / \mathrm{kg}$ ammoxetine) in the reserpine-treated rats. Duloxetine at a dose of $50 \mathrm{mg} / \mathrm{kg}$ significantly increased the levels of 5-HT (one-way ANOVA, $F_{2,15}=5.092, P=0.0205$, Dunn's Multiple Comparison Test, $P<0.05$ ) and NE (one-way ANOVA, $F_{2,15}=7.398, P=0.0058$, Dunn's Multiple Comparison Test, $P<0.01)$ and decreased the 5-HIAA/5-HT ratio (Kruskal-Wallis test, Kruskal-Wallis 

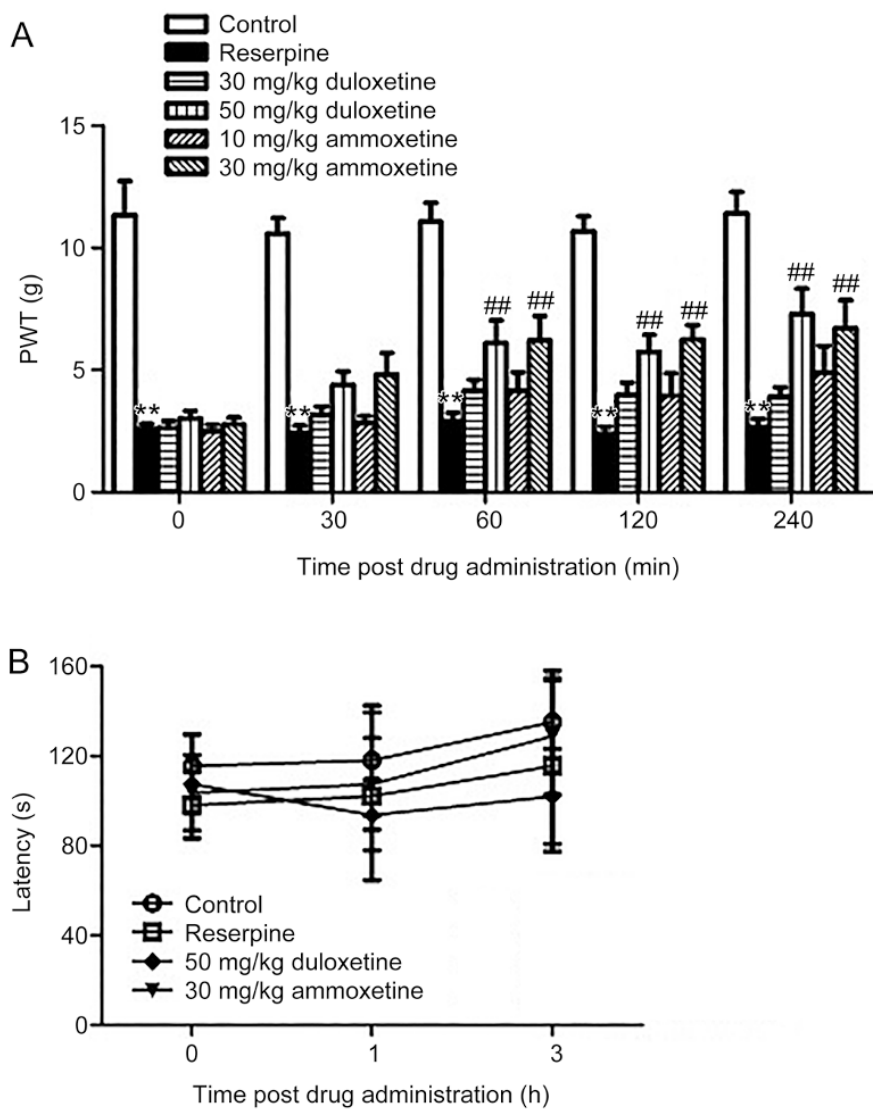

Figure 5. Analgesic effects of ammoxetine on reserpine-induced fibromyalgia. (A) Ammoxetine increased the PWT measured by the von Frey Hair test. (B) Time course of the effects of ammoxetine and duloxetine on the rotarod test in rats pretreated with reserpine $(n=6)$. Data are presented as the mean \pm SEM. $n=10 .{ }^{* * *} P<0.01$ vs the healthy control group at the same time point. ${ }^{\# \#} P<0.01$ vs the reserpine-treated group at the same time point.

statistic $=10.71, P=0.0047$, Dunn's Multiple Comparison Test, $P<0.01$ ) (Table 2).

In the hypothalamus, ammoxetine at a dose of $30 \mathrm{mg} / \mathrm{kg}$ increased the levels of 5-HT (one-way ANOVA, $F_{2,15}=3.915$, $P=0.0428$, Dunn's Multiple Comparison Test, $P<0.05)$ and NE (one-way ANOVA, $F_{2,13}=3.941, P=0.0459$, Dunn's Multiple Comparison Test, $P<0.05)$. Ammoxetine significantly reversed the effects of reserpine on the 5-HIAA/5-HT ratio (one-way ANOVA, $F_{2,15}=38.48, P<0.01$, Dunn's Multiple Comparison Test, $P<0.01$ for $10 \mathrm{mg} / \mathrm{kg}$ ammoxetine, $P<0.01$ for 30 $\mathrm{mg} / \mathrm{kg}$ ammoxetine). Duloxetine increased the levels of 5-HT (Kruskal-Wallis test, Kruskal-Wallis statistic $=7.825, P=0.0200$, Dunn's Multiple Comparison Test, $P<0.05$ for $50 \mathrm{mg} / \mathrm{kg}$ duloxetine) and decreased the 5-HIAA/5-HT ratio (one-way ANOVA, $F_{2,15}=52.47, P<0.01$, Dunn's Multiple Comparison Test, $P<0.01$ for $30 \mathrm{mg} / \mathrm{kg}$ duloxetine, $P<0.01$ for $50 \mathrm{mg} / \mathrm{kg}$ duloxetine) (Table 2).

In the thalamus, ammoxetine significantly increased the levels of NE (Kruskal-Wallis test, Kruskal-Wallis statistic $=8.157$, $P=0.0169$, Dunn's Multiple Comparison Test, $P<0.05$ for 30 $\mathrm{mg} / \mathrm{kg}$ ammoxetine). Ammoxetine significantly reversed the effects of reserpine on the 5-HIAA/5-HT ratio (one-way ANOVA, $F_{2,15}=10.26, P=0.0016$, Dunn's Multiple Comparison Test, $P<0.01$ for $10 \mathrm{mg} / \mathrm{kg}$ ammoxetine, $P<0.01$ for $30 \mathrm{mg} / \mathrm{kg}$ ammoxetine). Duloxetine increased the levels of 5-HT (oneway ANOVA, $F_{2,14}=3.743, P=0.0499$, Dunn's Multiple Comparison Test, $P<0.05$ for $30 \mathrm{mg} / \mathrm{kg}$ duloxetine) and NE (one-way ANOVA, $F_{2,13}=5.276, P=0.0210$, Dunn's Multiple Comparison Test, $P<0.05$ for $50 \mathrm{mg} / \mathrm{kg}$ duloxetine) and decreased the 5-HIAA/5-HT ratio (Kruskal-Wallis test, Kruskal-Wallis statistic $=11.38, P=0.0034$, Dunn's Multiple Comparison Test, $P<0.01$ for $30 \mathrm{mg} / \mathrm{kg}$ duloxetine, $P<0.05$ for $50 \mathrm{mg} / \mathrm{kg}$ duloxetine) (Table 2).

In the prefrontal cortex, ammoxetine increased the levels of 5-HT (one-way ANOVA, $F_{2,15}=5.233, P=0.0189$, Dunn's Multiple Comparison Test, $P<0.05$ for $10 \mathrm{mg} / \mathrm{kg}$ ammoxetine, $P<0.05$ for $30 \mathrm{mg} / \mathrm{kg}$ ammoxetine) and NE (one-way ANOVA, $F_{2,15}=16.66, P=0.0002$, Dunn's Multiple Comparison Test, $P<0.01$ for $10 \mathrm{mg} / \mathrm{kg}$ ammoxetine, $P<0.001$ for 30 $\mathrm{mg} / \mathrm{kg}$ ammoxetine) and decreased the 5-HIAA/5-HT ratio (one-way ANOVA, $F_{2,15}=7.140, P=0.0066$, Dunn's Multiple Comparison Test, $P<0.05$ for $10 \mathrm{mg} / \mathrm{kg}$ ammoxetine, $P<0.01$ for $30 \mathrm{mg} / \mathrm{kg}$ ammoxetine). Duloxetine increased the levels of 5-HT (Kruskal-Wallis test, Kruskal-Wallis statistic $=8.526$, $P=0.0141$, Dunn's Multiple Comparison Test, $P<0.05$ for 30 $\mathrm{mg} / \mathrm{kg}$ duloxetine) and NE (Kruskal-Wallis test, KruskalWallis statistic $=10.40, P=0.0055$, Dunn's Multiple Comparison Test, $P<0.01$ for $50 \mathrm{mg} / \mathrm{kg}$ duloxetine) and decreased the 5 -HIAA/5-HT ratio (one-way ANOVA, $F_{2,15}=20.92, P<0.01$, Dunn's Multiple Comparison Test, $P<0.01$ for $30 \mathrm{mg} / \mathrm{kg}$ duloxetine, $P<0.001$ for $50 \mathrm{mg} / \mathrm{kg}$ duloxetine) (Table 2).

Neither ammoxetine nor duloxetine displayed any effect on the levels of DA or on the DOPAC/DA ratio in the hypothalamus, thalamus or prefrontal cortex in reserpine-treated rats.

\section{Discussion}

In this study, ammoxetine displayed potent efficacy in preventing acetic acid-induced visceral inflammatory pain and formalin-induced continuous pain as demonstrated by lower $\mathrm{ED}_{50}$ values. Moreover, ammoxetine was efficacious in relieving neuropathic pain resulting from sciatic nerve injury (SNI and $\mathrm{CCI}$ ) and fibromyalgia induced by reserpine in rats. Furthermore, the efficacy of ammoxetine in neuropathic pain relief in the CCI and fibromyalgia models was dependent on 5-HT and NE.

Acetic acid-induced writhing, which might be considered a model of visceral inflammatory pain, is a commonly used pain test suitable for the evaluation of the action sites of antinociceptive drugs at the supraspinal level. These results are in accordance with previous studies that demonstrated that antidepressants, including fluoxetine, duloxetine and imipramine produced antinociceptive effects in the acetic acid-induced writhing test in mice ${ }^{[36,37]}$.

Previous studies identified the antinociceptive capacity of antidepressants, including the SNRIs milnacipran and duloxetine, in relieving the pain induced by formalin ${ }^{[38]}$. The data 
Table 2. Effect of ammoxetine on the contents of monoamines in the spinal cord and brain in reserpine-treated rats (pmol/mg). Data are presented as the mean \pm SEM. $n=10$. ${ }^{*} P<0.05,{ }^{* *} P<0.01$ versus the healthy control group at the same time point. ${ }^{\#} P<0.05$, ${ }^{\#} P<0.01$ versus the reserpine-treated group at the same time point.

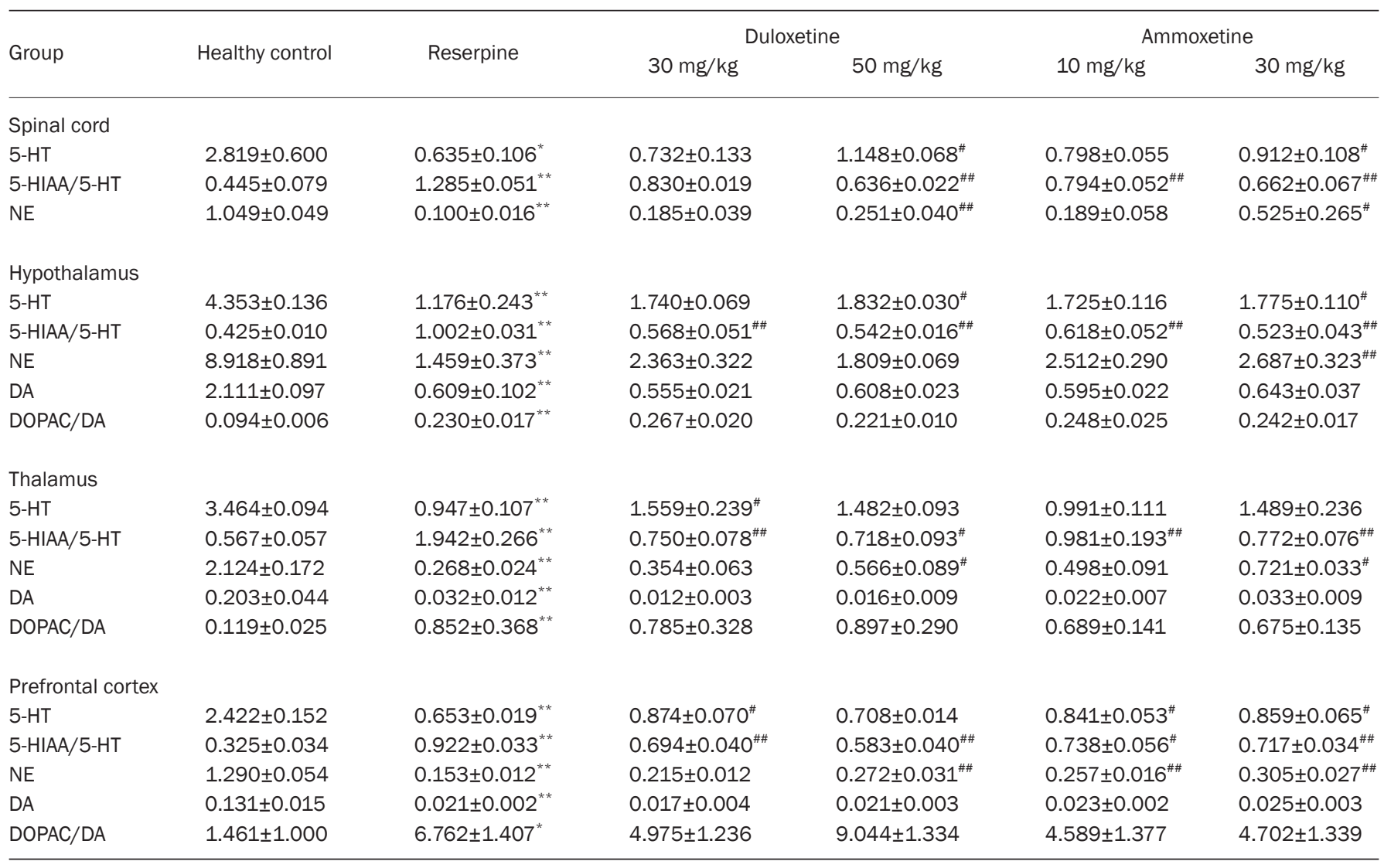

in the present study showed that ammoxetine and duloxetine were efficacious in reducing paw licking time in the first and second phases, with lower $\mathrm{ED}_{50}$ values in the second phase. This finding is consistent with the data reported by Bardin et al, which show that duloxetine and milnacipran reduced formalin-induced nociceptive behavior in the two phases with a more potent reduction in the second phase ${ }^{[39]}$. The second phase of formalin-induced licking behavior is considered to be pain associated with the function of spinal cord neurons, which are under the regulation of the descending pain transmission pathways ${ }^{[40]}$. Therefore, the analgesic effect of ammoxetine and duloxetine might be due to the potentiation of 5-HT and NE transmission in this model of pain. Lyengar et al demonstrated that either the selective NRI thionisoxetine or the SSRI paroxetine alone failed to reduce the late-phase licking in the formalin pain model, even at a dose that significantly elevated the neurotransmitters. However, lower doses of paroxetine and thionisoxetine administered together resulted in a statistically significant attenuation of the formalin-induced late-phase response ${ }^{[38]}$. These data suggest that the combined increase of 5-HT and NE might be more beneficial in the attenuation of persistent pain than an increase in either agent alone.

Ammoxetine significantly attenuated the neuropathic pain
30 min after administration in the SNI model, whereas the effect of duloxetine $(10 \mathrm{mg} / \mathrm{kg})$ was detected at the time point of $60 \mathrm{~min}$. This finding indicated that ammoxetine had a faster onset of analgesia than duloxetine in this neuropathic pain model. In the CCI model of neuropathic pain, the acute administration of ammoxetine significantly attenuated both the mechanical allodynia and the thermal hyperalgesic behavior. The potency of ammoxetine $(10 \mathrm{mg} / \mathrm{kg})$ was comparable to that of gabapentin $(60 \mathrm{mg} / \mathrm{kg})$. Duloxetine at a dose of 10 $\mathrm{mg} / \mathrm{kg}$ merely decreased mechanical allodynia in CCI rats at $120 \mathrm{~min}$ after administration. The results presented herein indicate that ammoxetine is more efficacious in suppressing neuropathic pain induced by CCI than duloxetine, as evidenced by lower minimal effective doses. The analgesic effects of SNRIs on neuropathic pain were estimated in several animal models. However, discordant conclusions were drawn from these studies. The study of Murai et al found that duloxetine significantly ameliorated mechanical allodynia at a dose of $30 \mathrm{mg} / \mathrm{kg}^{[41]}$. The study of Bomholt et al showed that duloxetine $(30 \mathrm{mg} / \mathrm{kg}$ ) significantly attenuated thermal hyperalgesia but failed to reduce mechanical allodynia in response to von Frey hair stimuli in CCI rats ${ }^{[42]}$. The results from the studies of Le Cudennec showed that duloxetine at a dose of 
$50 \mathrm{mg} / \mathrm{kg}$ significantly inhibited mechanical hyperalgesia and heat hyperalgesia but not mechanical allodynia in CCI rats ${ }^{[43]}$. These discrepancies regarding the acute efficacy of duloxetine on mechanical allodynia might be related to the experimental protocols and the doses of the drug used in the various studies.

We also evaluated the involvement of the serotonergic or noradrenergic mechanisms underlying the antiallodynic effect of ammoxetine using two monoamine-depleting agents in the CCI model. PCPA, which inhibits the tryptophan hydroxylase enzyme, has been reported to inhibit the synthesis of 5-HT and deplete the endogenous stores of 5-HT in the central nervous system $(\mathrm{CNS})^{[44]}$. As shown in this study, the administration of PCPA abolished the antiallodynic effect of ammoxetine. This result indicates that 5-HT plays a critical role in the pharmacological effect of ammoxetine. The results from Umut et al demonstrated that PCPA administration did not reverse the antiallodynic effects of mianserin, another SNRI agent, in a diabetic neuropathy model of rats ${ }^{[45]}$. The difference in the 5-HT reuptake inhibition efficiency between ammoxetine and mianserin might be correlated to these different results. It is also possible that the mechanisms related to the antinociceptive actions of antidepressants might differ between different animal models.

The relationship between NE and the effect of ammoxetine was examined using AMPT, which selectively inhibits tyrosine hydroxylase and decreases the synthesis of NE and DA. It has previously been reported that the dual administration (with a $23 \mathrm{~h}$ interval) of AMPT at $200 \mathrm{mg} / \mathrm{kg}$ induced a $50 \%-60 \%$ reduction in the CNS NE level ${ }^{[46]}$. In the present study, we found that AMPT treatment abolished the antiallodynic effects of ammoxetine in CCI rats. In addition, our previous research demonstrated that ammoxetine was a potent inhibitor of the uptake of 5-HT and NE, whereas it had no effect on DA levels. This finding suggests that the antiallodynic effect of ammoxetine is at least partially related to a NE enhancement mechanism. These studies indicate that a sufficient elevation of 5-HT and NE might be required for effective pain relief by antidepressants. The pronounced analgesic effect of ammoxetine on neuropathic pain in rats might be attributed to its robust inhibition of 5-HT and NE reuptake.

Fibromyalgia is a complex of syndromes and is difficult to treat. Only three drugs, pregabalin, duloxetine and milnacipran, have been approved for its treatment by the US FDA. Duloxetine is recommended as the first choice for the treatment of fibromyalgia ${ }^{[23]}$. However, there is limited evidence for the efficacy of antidepressants in preclinical pain-models of fibromyalgia. Although the exact molecular mechanisms underlying the CNS sensitization and the painful symptoms of fibromyalgia remain to be elucidated, evidence indicates that the pathophysiology of fibromyalgia is related to the dysfunction of biogenic amine-mediated pain control pathways in the $\mathrm{CNS}^{[47,48]}$. Nagakura et al developed a chronic-pain animal model with a dysfunctional biogenic amine system induced by reserpine that mimics fibromyalgia in humans ${ }^{[34]}$. That group reported that duloxetine at a dose of $30 \mathrm{mg} / \mathrm{kg}$ significantly relieved the muscle pressure but not the tactile allodynia in this model. In our present study, the acute administration of ammoxetine $(30 \mathrm{mg} / \mathrm{kg}$ ) and duloxetine $(50 \mathrm{mg} / \mathrm{kg})$ attenuated the tactile allodynia in the model established according to the methods of Nagakura et al. Furthermore, we confirmed that reserpine caused a significant decrease in biogenic amines (DA, NE, and 5-HT) and increased the 5-HIAA/5-HT and DOPAC/DA ratios in the spinal cord, hypothalamus, thalamus and prefrontal cortex. These central nervous system regions are deeply involved in descending inhibitory pain signal processing. The administration of ammoxetine or duloxetine increased the levels of 5-HT and NE, but not DA, and decreased the 5-HIAA/5-HT ratio in the spinal cord and brain regions. Under normal circumstances, SNRIs increase the extra-cellular concentration of 5-HT and NE by blocking the reuptake of these monoamines, although the total amount of monoamines might not be changed significantly. The effect of reserpine might make it clearer that SNRIs increase the total content of 5-HT and NE by keeping these neurotransmitters in the extra-cellular space and reducing their oxidation, which could be supported by the decreased 5-HT metabolic rate in the tissues. These results support the hypothesis that the inhibition of 5-HT and NE reuptake might be responsible for the antiallodynic effects of ammoxetine and duloxetine in the fibromyalgia model. The data from the present study and the study of Nagakura et al suggest that a high dose of duloxetine is needed for significant antiallodynic effects in this pain model. These results also suggest that strong inhibition of 5-HT and NE reuptake is necessary for drug efficacy. This study provides the evidence that SNRIs display antiallodynic effects dependent on an increase in 5-HT and NE levels in the descending inhibitory pathways in an animal model of fibromyalgia.

\section{Conclusion}

The present study suggests that ammoxetine produces more potent analgesic effects than duloxetine in animal models of inflammatory and continuous pain. Ammoxetine also had an analgesic effect on neuropathic pain induced by SNI or CCI and on pain associated with fibromyalgia induced by reserpine. The pain-relieving mechanisms of ammoxetine could be attributed to an increase in the transmission of 5-HT and NE in the descending inhibitory pathways. Given the impressive analgesic effects of ammoxetine, we consider the potential effect and strategies directed to the treatment of neuropathic pain and fibromyalgia.

\section{Abbreviations}

5-HT, serotonin; NE, norepinephrine; SNRIs, selective serotonin and norepinephrine reuptake inhibitors; 5-HIAA, 5-hydroxyindole-3-acetic acid; HVA, homovanillic acid; DOPAC, 3,4-dihydroxyphenylacetic acid; SNI, sciatic nerve injury; CCI, chronic constriction injury; TCAs, tricyclic antidepressants; SSRIs, selective serotonin reuptake inhibitors; NRIs, norepinephrine reuptake inhibitors. 


\section{Acknowledgements}

This work was supported by the National Key New Drug Creation Program (No 2012ZX09102101-004) and the National Natural Science Foundation of China (№ 81302761, 81274117, and 30973516).

\section{Author contribution}

Ting-ting ZHANG contributed to the research design, performance of the experiments, data analysis and manuscript writing. Rui XUE contributed to research design and manuscript revision. Juan LI and Qiong-yin FAN participated in the behavioral tests and manuscript revision. Bo-hua ZHONG and Yun-feng LI contributed to the manuscript revision. Lei ZHU helped in manuscript revision. You-zhi ZHANG and Cai-ying YE contributed to the research design and manuscript revision.

\section{References}

1 Bair MJ, Robinson RL, Katon W, Kroenke K. Depression and pain comorbidity: a literature review. Arch Intern Med 2003; 163: 243345.

2 Leo RJ. Chronic pain and comorbid depression. Curr Treat Options Neurol 2005; 7: 403-12.

3 Cayley WE Jr. Antidepressants for the treatment of neuropathic pain. Am Fam Physician 2006; 73: 1933-4.

4 Mico JA, Ardid D, Berrocoso E, Eschalier A. Antidepressants and pain. Trends Pharmacol Sci 2006; 27: 348-54.

5 Finnerup NB, Sindrup SH, Jensen TS. The evidence for pharmacological treatment of neuropathic pain. Pain 2010; 150: 573-81.

6 Yarnitsky D. Role of endogenous pain modulation in chronic pain mechanisms and treatment. Pain 2015; 156: 24-31.

7 Thor KB, Kirby M, Viktrup L. Serotonin and noradrenaline involvement in urinary incontinence, depression and pain: scientific basis for overlapping clinical efficacy from a single drug, duloxetine. Int J Clin Pract 2007; 61: 1349-55.

8 Bannister K, Bee LA, Dickenson AH. Preclinical and early clinical investigations related to monoaminergic pain modulation. Neurotherapeutics 2009; 6: 703-12.

9 An update on the drug treatment of neuropathic pain. Part 1: antidepressants. Drug Ther Bull 2012; 50: 114-7.

10 O'Connor AB, Dworkin RH. Treatment of neuropathic pain: an overview of recent guidelines. Am J Med 2009; 122: 22-32.

11 Liu WQ, Kanungo A, Toth C. Equivalency of tricyclic antidepressants in open-label neuropathic pain study. Acta Neurol Scand 2014; 129: 132-41.

12 Anderson IM. Selective serotonin reuptake inhibitors versus tricyclic antidepressants: a meta-analysis of efficacy and tolerability. J Affect Disord 2000; 58: 19-36.

13 Lee YC, Chen PP. A review of SSRIs and SNRIs in neuropathic pain. Expert Opin Pharmacother 2010; 11: 2813-25.

14 Jung AC, Staiger T, Sullivan M. The efficacy of selective serotonin reuptake inhibitors for the management of chronic pain. J Gen Intern Med 1997; 12: 384-9.

15 Dharmshaktu P, Tayal V, Kalra BS. Efficacy of antidepressants as analgesics: a review. J Clin Pharmacol 2012; 52: 6-17.

16 Dworkin RH, O'Connor AB, Backonja M, Farrar JT, Finnerup NB, Jensen TS, et al. Pharmacologic management of neuropathic pain: evidencebased recommendations. Pain 2007; 132: 237-51.

17 Lunn MP, Hughes RA, Wiffen PJ. Duloxetine for treating painful neuro- pathy, chronic pain or fibromyalgia. Cochrane Database Syst Rev 2014; 1: 1-121.

18 Watson CP, Gilron I, Sawynok J, Lynch ME. Nontricyclic antidepressant analgesics and pain: are serotonin norepinephrine reuptake inhibitors (SNRIs) any better? Pain 2011; 152: 2206-10.

19 Smith T, Nicholson RA. Review of duloxetine in the management of diabetic peripheral neuropathic pain. Vasc Health Risk Manag 2007; 3: 833-44.

20 Pergolizzi JV Jr, Raffa RB, Taylor R Jr, Rodriguez G, Nalamachu S, Langley P. A review of duloxetine $60 \mathrm{mg}$ once-daily dosing for the management of diabetic peripheral neuropathic pain, fibromyalgia, and chronic musculoskeletal pain due to chronic osteoarthritis pain and low back pain. Pain Pract 2013; 13: 239-52.

21 Arnold LM, Rosen A, Pritchett YL, D'Souza DN, Goldstein DJ, lyengar $\mathrm{S}$, et al. A randomized, double-blind, placebo-controlled trial of duloxetine in the treatment of women with fibromyalgia with or without major depressive disorder. Pain 2005; 119: 5-15.

22 Bymaster FP, Dreshfield-Ahmad $\sqcup$, Threlkeld PG, Shaw JL, Thompson $\mathrm{L}$, Nelson DL, et al. Comparative affinity of duloxetine and venlafaxine for serotonin and norepinephrine transporters in vitro and in vivo, human serotonin receptor subtypes, and other neuronal receptors. Neuropsychopharmacology 2001; 25: 871-80.

23 Koch S, Hemrick-Luecke SK, Thompson LK, Evans DC, Threlkeld PG, Nelson DL, et al. Comparison of effects of dual transporter inhibitors on monoamine transporters and extracellular levels in rats. Neuropharmacology 2003; 45: 935-44.

24 Bel N, Artigas F. Modulation of the extracellular 5-hydroxytryptamine brain concentrations by the serotonin and noradrenaline reuptake inhibitor, milnacipran. Microdialysis studies in rats. Neuropsychopharmacology 1999; 21: 745-54.

25 Xue R, He XH, Yuan L, Chen HX, Zhang LM, Yong Z, et al. Effects of 071031B, a novel serotonin and norepinephrine reuptake inhibitor, on monoamine system in mice and rats. J Pharmacol Sci 2016; 130: $1-7$.

26 Xue R, Jin ZL, Chen HX, Yuan L, He XH, Zhang YP, et al. Antidepressant-like effects of $071031 \mathrm{~B}$, a novel serotonin and norepinephrine reuptake inhibitor. Eur Neuropsychopharmacol 2013; 23: 728-41.

27 Xue R, Zhang YP, Jin ZL, Yuan L, He XH, Zhao N, et al. The discovery of $071031 B$, a novel serotonin and noradrenaline reuptake inhibitor. Neurosci Lett 2013; 544: 68-73.

28 Satyanarayana PS, Jain NK, Singh A, Kulkarni SK. Isobolographic analysis of interaction between cyclooxygenase inhibitors and tramadol in acetic acid-induced writhing in mice. Prog Neuropsychopharmacol Biol Psychiatry 2004; 28: 641-9.

29 Shibata M, Ohkubo T, Takahashi H, Inoki R. Modified formalin test: characteristic biphasic pain response. Pain 1989; 38: 347-52.

30 Decosterd I, Woolf CJ. Spared nerve injury: an animal model of persistent peripheral neuropathic pain. Pain 2000; 87: 149-58.

31 Bennett GJ, Xie YK. A peripheral mononeuropathy in rat that produces disorders of pain sensation like those seen in man. Pain 1988; 33: 87-107.

32 Chaplan SR, Bach FW, Pogrel JW, Chung JM, Yaksh TL. Quantitative assessment of tactile allodynia in the rat paw. J Neurosci Methods 1994; 53: 55-63.

33 Hargreaves K, Dubner R, Brown F, Flores C, Joris J. A new and sensitive method for measuring thermal nociception in cutaneous hyperalgesia. Pain 1988; 32: 77-88.

34 Nagakura Y, Oe T, Aoki T, Matsuoka N. Biogenic amine depletion causes chronic muscular pain and tactile allodynia accompanied by depression: A putative animal model of fibromyalgia. Pain 2009; 146: 
26-33.

35 Kaneko K, Umehara M, Homan T, Okamoto K, Oka M, Oyama T. The analgesic effect of tramadol in animal models of neuropathic pain and fibromyalgia. Neurosci Lett 2014; 562: 28-33.

36 Aoki M, Tsuji M, Takeda H, Harada Y, Nohara J, Matsumiya T, et al. Antidepressants enhance the antinociceptive effects of carbamazepine in the acetic acid-induced writhing test in mice. Eur J Pharmacol 2006; 550: 78-83.

37 Korzeniewska-Rybicka I, Plaznik A. Analgesic effect of antidepressant drugs. Pharmacol Biochem Behav 1998; 59: 331-8.

38 Lyengar S, Webster AA, Hemrick-Luecke SK, Xu JY, Simmons RM. Efficacy of duloxetine, a potent and balanced serotonin-norepinephrine reuptake inhibitor in persistent pain models in rats. J Pharmacol Exp Ther 2004; 311: 576-84.

39 Bardin L, Gregoire S, Aliaga M, Malfetes N, Vitton O, Ladure P, et al. Comparison of milnacipran, duloxetine and pregabalin in the formalin pain test and in a model of stress-induced ultrasonic vocalizations in rats. Neurosci Res 2010; 66: 135-40.

40 Chen HS, Li MM, Shi J, Chen J. Supraspinal contribution to development of both tonic nociception and referred mirror hyperalgesia: a comparative study between formalin test and bee venom test in the rat. Anesthesiology 2003; 98: 1231-6.

41 Murai N, Aoki T, Tamura S, Sekizawa T, Kakimoto S, Tsukamoto M, et al. AS1069562, the (+)-isomer of indeloxazine, exerts analgesic effects in a rat model of neuropathic pain with unique characteristics in spinal monoamine turnover. J Pharmacol Exp Ther 2014; 348: 372-82.

42 Bomholt SF, Mikkelsen JD, Blackburn-Munro G. Antinociceptive effects of the antidepressants amitriptyline, duloxetine, mirtazapine and citalopram in animal models of acute, persistent and neuropathic pain. Neuropharmacology 2005; 48: 252-63.

43 Le Cudennec C, Castagne V. Face-to-face comparison of the predictive validity of two models of neuropathic pain in the rat: analgesic activity of pregabalin, tramadol and duloxetine. Eur J Pharmacol 2014; 735: 17-25.

44 Prinssen EP, Assie MB, Koek W, Kleven MS. Depletion of 5-HT disrupts prepulse inhibition in rats: dependence on the magnitude of depletion, and reversal by a 5-HT precursor. Neuropsychopharmacology 2002; 26: 340-7.

45 Ucel UI, Can OD, Demir Ozkay U, Ozturk Y. Antihyperalgesic and antiallodynic effects of mianserin on diabetic neuropathic pain: a study on mechanism of action. Eur J Pharmacol 2015; 756: 92-106.

46 Corrodi H, Hanson LC. Central effects of an inhibitor of tyrosine hydroxylation. Psychopharmacologia 1966; 10: 116-25.

47 Wood PB, Holman AJ, Jones KD. Novel pharmacotherapy for fibromyalgia. Expert Opin Investig Drugs 2007; 16: 829-41.

48 Yunus MB. Fibromyalgia and overlapping disorders: the unifying concept of central sensitivity syndromes. Semin Arthritis Rheum 2007; 36: 339-56. 